\title{
The Integration of Cultural Industry and Tourism in Last Ten Years in Shandong Province, China
}

\author{
Zhuoqun $\mathrm{Du}^{*}$ and Peilin $\mathrm{Wu}$ \\ School of Business Studies, Shandong University, Weihai 264209, China \\ *Corresponding author. E-mail:duzhuoqun@126.com

\begin{abstract}
As the integration of cultural industry and tourism turns to be a public trend in China, some scholars and agencies are paying attention to the methods to evaluate the degree or level of the integration. Shandong is a province with rich cultural resources, large-scale cultural industry and tourism. It has experienced the integration process of cultural industry and tourism for about 10 years. So the authors choose it as a case study area to evaluate the integration levels, classify the integration types, and try to forward practical policy measures. The authors establish a valuation system with 23 indicators, using a coupled coordinated dispatch model to quantify the integration of cultural industry and tourism in the province. The proposed policy measures aim to promote the development of cultural industrial and tourism as well as their substantial integration in the case area and other similar regions.
\end{abstract}

Keywords: Cultural industry, Tourism, Industrial Convergence, integration type, Coupling coordination degree model, Shandong Province.

\section{INTRODUCTION}

The development of cultural industry and tourism is of great importance to both national and regional high-quality development strategy. Shandong is one of the largest provinces both in population and gross domestic production in China. With profound natural and cultural heritage, Shandong's overall scale of tourism development ranks first in the country. By the end of 2019, Shandong Province has 2,630 travel agencies, 637 star-rated hotels, 1,229 A-level scenic spots, including $115 \mathrm{~A}$-level scenic spots, and has 376 provincial and national industrial tourism demonstration sites. The province holds a few influential national and international cultural or artistic festivals every year or every two years, such as the International Confucius Cultural Festival in Qufu city and the International Mount Tai Climbing Festival in Tai'an city. In addition, it has 105 arts and cultural performing groups, 575 museums, 154 public libraries, 157 mass art galleries and cultural centers. Moreover, there are 173 cultural heritage items, ranking second among the provinces of the country.

The cultural industry and tourism are naturally developed with convergences. Culture is the soul of tourism and can enhance the creative connotation and core value of the tourism industry [1]. In recent years, Jinan City's artistic and cultural theme parks have developed rapidly. Qufu City takes the Confucian Mansion culture as core element and experience material to carry out distinctive education tourism. Qingzhou city relies on its ancient city heritage of Ming and Qing Dynasties attracting more and more national and foreign visitors. Zibo city has built a tourism brand relying on the advantages of Qi style culture. The coastal cities such as Qingdao, Yantai and Weihai have integrated seaside culture into the tourism industry to create seaside characteristic tourism business as their city cards.

In 2019, Shandong's total tourism revenue was 1108.73 billion RMB, an increase of $12.1 \%$ over the previous year; meanwhile, a total of 93.093 million domestic and foreign tourists were received, an increase of $8.6 \%$ over the previous year. In 2018, the total revenue of the province's tourism industry was 9892.4 billion RMB, and the total tourism output value accounted for $13.7 \%$ of its domestic gross production, which is equivalent to $27.6 \%$ of the tertiary industry output. These data show that both the number of tourists and tourism income in Shandong has increased significantly, and the integrated development of cultural industry and tourism has achieved initial progress. 
According to the provincial development plan, the government aims to develop cultural industry as one of the primary economic and social features, and will put effort into constructing demonstrative tourism destinations and cultural sites. Therefore, measuring the current level of integration between the cultural industry and tourism in Shandong has important practical significance, and can provide theoretical and data support for the formulation of policies to promote the in-depth integration of cultural industry and tourism.

\section{INDEX CONSTRUCTION AND EVALUATION METHODS}

Next, the authors describe in detail how to construct an indicator system, how to process data, and then prepare for the integration of cultural and travel measures.

\subsection{The Index System of Cultural Industry and Tourism}

With the deepening of research on cultural industry and tourism integration, some scholars have turned their research focus to the evaluation of regional cultural industry and tourism integration. As is known, the essence of cultural and tourism integration is industrial convergence. Hou Bing (2015) built an indicator system of tourism and cultural industry development from two aspects, industrial performance level and industrial element level, each including a few indicators in terms of business income, agency numbers, employees and human resource and so on, and then used the coupling coordination model to evaluate the integration of cultural industry and tourism in the Yangtze River Delta area [2]. After analyzing the integration development mechanism of tourism and cultural industry, Weng Gangmin constructed a five-dimension industry development indicator system including general data, business agencies, employees, business income using the coupled coordination degree model and exploratory data analysis method, and discussed the two industries' development situation, trend and spatial correlation degree of 31 provinces in China [3]. Zhou Bin (2019) selected 21 indicators and constructed industrial development index system based on the tourism and cultural industry development data in Inner Mongolia, and then evaluated its integration level of the two industries through the coupling coordination model [4].
Though different methods are used in the above study, the first step to evaluate the degree of cultural industry and tourism integration in the region is to quantitatively analyze the development of both cultural industry and tourism. Referring to the results of above studies and actual situation of the case area, we manage to establish a revised cultural industry and tourism integration index system in order to evaluate the industrial convergence of the province, as displayed in Table 1. There are several principles when building the index system. Firstly, the industrial development indicator system should involve a series of factors that affect industrial development, which can fully and objectively reflect the level of industrial development though the quantification of these factors is by no means exhaustive. We tried to select representative factors to calculate the index and avoid potential overlap between indices. Secondly, rationality and accuracy are highly required and all data must come from authoritative sources. The database and indices should have the attribute of availability, measurability, comparability and operability at the same time, in order that the research results can be reliable and accepted easily by decision-making departments.

According to the input-output concept of business activities and the development status of Shandong's cultural industry and tourism industry, we select 23 indicators to build an evaluation index system for the province's tourism and cultural industry development analysis. In terms of input, we mainly consider the human and material inputs in tourism industry and the cultural industry, so we select the number of employees and the number of related business agencies as indicators. In terms of output, tourism is mainly to provide people with touring services from the perspective of social benefits, so the authors choose the number of domestic and foreign tourists as the tourism output indicator. The cultural industry mainly acts as a cultural dissemination in tourist destinations and provides cultural experience for tourists. Therefore, we select the number of cultural heritage and the number of visitors to cultural properties as evaluation indicators. From the perspective of economic benefits, the business goals of both industries are to increase output value, so the authors select income of tourism and cultural industry's related departments as the indicator 
Table 1. Industrial Development Index System and the Weights of Indices

\begin{tabular}{|c|c|c|}
\hline Industry & Dimension & Index \\
\hline Tourism & $\begin{array}{c}\text { Input } \\
(0.264)\end{array}$ & $\begin{array}{l}\text { Number of travel agencies; Number of star-rated hotels; } \\
\text { Number of scenic spots above 4A; Number of travel agency employees; } \\
\text { Number of students in tourism colleges; Number of employees in star-rated hotels }\end{array}$ \\
\hline Tourism & $\begin{array}{l}\text { Output } \\
(0.736)\end{array}$ & $\begin{array}{c}\text { Tourism income; Number of inbound tourists; Number of domestic tourists; } \\
\text { Travel agency income; Star-rated hotel revenue; Inbound tourism income; } \\
\text { Domestic tourism income }\end{array}$ \\
\hline Cultural & $\begin{array}{c}\text { Input } \\
(0.309)\end{array}$ & $\begin{array}{l}\text { Number of libraries; Number of public cultural centers; Number of library } \\
\text { employees; Number of museums; Number of art performance groups; } \\
\text { Number of museum employees; Number of employees in theatrical performances }\end{array}$ \\
\hline Cultural & $\begin{array}{l}\text { Output } \\
(0.691)\end{array}$ & $\begin{array}{c}\text { Number of cultural heritages; Museum income; Cultural business expenses; } \\
\text { Added value of cultural industry; Number of visitors to the cultural Property; } \\
\text { Performance income of art performance groups } \\
\text { Income of cultural market operating institutions }\end{array}$ \\
\hline
\end{tabular}

\subsection{Data Processing and Evaluation Methods}

Due to various types and data sources of the indices, the order of magnitude and dimension of the indices are different from each other. Before calculating and making comparison, we standardize the indicator matrix to obtain standardized matrix $Y_{i j}$. The first step is to use the entropy method to obtain the weight $W_{j}$ of each indicator, and construct the weighted norm matrix $R_{i j}\left(R_{i j}=Y_{i j} * W_{j}\right)$. The indicator weights are displayed in Table 1.

The step two is to use TOPSIS method to calculate the industrial development level. Determine the positive ideal value $\mathrm{Sep}^{+}$and negative ideal value $\mathrm{Sep}^{-}$of the evaluation target, and then calculate the Euclidean distance $S^{+}$and $S^{-}$between the target value and the ideal value, and finally find the relative link degree $C$ of each scheme and the ideal solution. $C$ represents the industry development index.

$C=\frac{s^{-}}{S^{-}+S^{+}}$

The value of $C$ belongs to [0,1]. The larger the $C$, the higher the development level of tourism or cultural industry.

The step three is to measure the integration degree of cultural industry and tourism through the coupling coordination model.

$$
\begin{aligned}
& C T I_{i}=\sqrt{T_{i} * F_{i}} \\
& T_{i}=\sqrt{\frac{C_{t} C_{c}}{\left(C_{t}+C_{c}\right)^{2}}} \\
& F_{i}=W_{1} C_{t}+W_{2} C_{c}
\end{aligned}
$$

$C T I_{i}$ is the degree of coupling between the two industrial systems, and it is between 0 and 1 . The larger the $C T I_{i}$, the better the coupling. $T_{i}$ is the degree of coordination between tourism and cultural industry. $F_{i}$ is the comprehensive coordination index, reflecting the contribution of overall development level of the cultural industry or tourism to the integration. And $W_{1}$ and $W_{2}$ are the undetermined coefficient. We consider that the cultural industry and the tourism are equally important to economic development of the region, so they are set to 0.5 according to the practice of related scholars. $C_{c}$ and $C_{t}$ represent the development index of tourism industry and cultural industry.

We classify the integration degree of cultural industry and tourism in Shandong into different levels according to Liao Chongbin's classification standard for the degree of coupling and coordination [5]. If the degree belongs to $[0,0.5]$, the integration is at incoordination level. While the degree belongs to $[0.5,1]$, it is at coordination level. Specifically, the degree of incoordination can be divided into five levels including extreme, severe, moderate, mild and slight. Correspondingly, coordination includes low coordination, relatively coordination, basic coordination, high coordination, and extreme coordination.

\section{THE EVALUATION RESULTS}

We use the above evaluation method to calculate the cultural industry and tourism industry index and the degree of cultural industry and tourism integration in Shandong Province 2008 - 2018. The result of tourism industry index $\left(C_{t}\right)$, cultural industry index $\left(C_{c}\right)$, cultural 
industry and tourism integration degree $(C T I)$, and the related index $\left(C_{t} / C_{c}\right)$ are displayed in Table 2.

For the industrial development evaluation index, as a whole, the development level of the tourism industry and cultural industry in Shandong Province is on the rise. In the tourism industry subsystem, the tourism industry has grown steadily at an average annual growth rate of about $4 \%$, which benefits from the abundant tourism resources, convenient infrastructure and government policy support in Shandong.

In the cultural industry subsystem, as shown in Figure 1, the development of the cultural industry presents a tortuous growth. In 2009, the cultural industry development index was the lowest of 0.0246 , slightly lower than the previous year. Analyzing various industrial indicators, we found that the income of cultural market operating institutions decreased by $52.14 \%$ compared with 2008, and the other indicators are all increased year by year. The cultural industry development index reached a small peak in 2010 and has developed rapidly since 2011 . Policy support is an important reason for the rapid development of the cultural industry during this period. Since 2011, Shandong province has responded to the national call to vigorously develop cultural industry and introduced relevant policies and measures to promote the development of cultural industries. In recent years, the development speed of Shandong's cultural industry has continued to increase. In 2017 and 2018, the industrial growth rate was greater than $12 \%$ each year. The added value of the cultural industry has continued to increase, and its share of GDP has also increased year by year.

For the cultural industry and tourism integration, the development level of cultural industry and tourism integration in Shandong has been increasing year by year since 2008. The degree of cultural industry and tourism integration has increased from 0.2274 in 2008 to 0.6304 in 2018 , with an average annual growth rate of $8.8 \%$. At the same time, the cultural industry and tourism integration level has gradually improved from moderate incoordination to low coordination and then upgraded to relatively coordination. This shows that the integration between tourism and cultural industry in the case area has gradually changed from weak to strong.

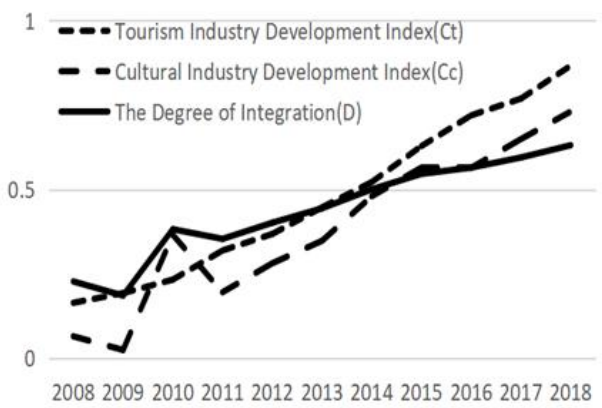

Figure 1 Coupling degree of cultural industry and tourism in Shandon

For the $C_{t} / C_{c}$ indicator, if its value is greater than 1 , it means that the development of the cultural industry is lagging behind the tourism industry, showing a state of cultural lagging integration. On the contrary, if the value of $C_{t} / C_{c}$ is less than 1 , it means that the tourism industry is lagging behind the development of the cultural industry, showing a state of tourism lagging integration. If the value of $C_{t} / C_{c}$ is equal or close to 1 , it represents the coordinated development of tourism and cultural industry, showing a state of coordinated integration of both industries. As is shown in Table 2, the value of $C_{t} / C_{c}$ is greater than 1 in Shandong from 2008 to 2018 , indicating that the overall development of the cultural industry lagged behind the tourism industry in last ten years. That is in a state of cultural lagging integration. The overall value of the tourism development index in Figure 1 is higher than the cultural industry development index, which also confirms the above conclusion. Benefiting from its rich natural and historical resources, the tourism in Shandong has long history and well developed, while the cultural industry has some problems and needs to accelerate its developing pace. In the past three years, the value of $C_{t} / C_{c}$ has stabilized at around 1.2 , indicating that there is still a certain gap between the development of cultural industry and the tourism in Shandong. Therefore, if Shandong wants to promote the integration of cultural industry and tourism, both the government and related business agencies must pay especially attention to improve the development of cultural industry.

\section{CONCLUSION AND SUGGESTIONS}

The authors establish a valuation system with 23 indicators, using a coupled coordinated dispatch model to evaluate the integration of cultural industry and tourism in Shandong Province. The results showed that the level of cultural industry and tourism integration in Shandong Province is gradually improved, but overall, it remains at a comparatively low level. In addition, the coupling coordination degree of the cultural industry and tourism is sustained on the low side. 
The results also showed that the development of cultural industry in general is slower than the tourism industry. Although the gap between the two industries continues to shrink, the development of the cultural industry still has a certain distance from the tourism industry. As realizing the coordinated development of cultural industry and tourism industry is the practical way to achieve deep integration of cultural industry and tourism, the unbalanced development of the two industries will inevitably hinder the level of integration of the two industries. Therefore, in the future, Shandong Province must increase support for cultural industry, thereby coupling the coordinated development of cultural industry and tourism industry, and then promoting the deep integration of culture industry and tourism industry.

According to the current situation of cultural industry and tourism integration in Shandong, we suggest the following strategies to improve the development and integration of cultural industry and tourism.

Firstly, Shandong should increase the protection and utilization of local cultural resources, especially the peculiar characteristic cultural resources. It is important to tell Shandong story well and carry out targeted cultural resource development and cultural product design in order to satisfy tourists spiritual and cultural needs, and providing rich cultural elements for cultural industry and tourism integration in turn. All the cultural resources should be overall planned to form a comprehensive development system, and then carry out the secondary development of cultural resources with a unique perspective.

Secondly, Shandong should increase efforts to cultivate high-quality cultural industry resources. High-quality cultural industry resources are not only the lifeline and vitality source of the cultural industry, but also an important way to enhance the attractiveness of the tourism industry and improve tourists' experience. Therefore, Shandong should accelerate the cultivation of high-quality cultural industry resources and provide high-quality cultural products for the integration of cultural industry and tourism achieve a well coordination state.

Thirdly, Shandong should speed up the training of compound talents in related majors. The tourism industry and the cultural industry are both highly creative industries, and having high-quality and high-level talents is an important condition for accelerating industrial development. Therefore, Shandong should increase the intensity of talent training and employ talents who can excavate and integrate cultural resources, create high-quality cultural content, and have an in-depth understanding of culture and tourism. As a result, the talent-driven development of the cultural industry and tourism integration could be gradually realized.

Table 2. Calculated results of cultural industry and tourism Integration indices

\begin{tabular}{|l|l|l|l|l|l|}
\hline Year & Cc & Ct & CTI & Integration level & Ct/Cc \\
\hline 2008 & 0.1641 & 0.065 & 0.2274 & Moderate incoordination & 2.5246 \\
\hline 2009 & 0.1928 & 0.0246 & 0.1855 & Severe incoordination & 7.8374 \\
\hline 2010 & 0.2328 & 0.3652 & 0.3818 & Mild incoordination & 0.6374 \\
\hline 2011 & 0.3189 & 0.1955 & 0.3533 & Mild incoordination & 1.6312 \\
\hline 2012 & 0.3678 & 0.2811 & 0.401 & Slight incoordination & 1.3084 \\
\hline 2013 & 0.4465 & 0.3476 & 0.4438 & Slight incoordination & 1.2845 \\
\hline 2014 & 0.5214 & 0.4793 & 0.4999 & Slight incoordination & 1.0878 \\
\hline 2015 & 0.628 & 0.5645 & 0.5456 & Low coordination & 1.1125 \\
\hline 2016 & 0.7188 & 0.5637 & 0.5642 & Low coordination & 1.2751 \\
\hline 2017 & 0.7683 & 0.6486 & 0.5941 & Low coordination & 1.1846 \\
\hline 2018 & 0.8657 & 0.73 & 0.6304 & Relatively coordination & 1.1859 \\
\hline
\end{tabular}




\section{REFERENCES}

[1] C.B. Zhou, The dynamic Mechanism and Synergy of the Integration of Culture Industry and Tourism, J. Social Scientist, 02(2018)99-103.

[2] B. Hou, X.Q. Zhao, Assessment and Evaluation of Integration of the Culture Industry and Tourism Industry in Yangtze River Delta, J. Economic Geography. 11(2015)211-217.

[3] G.M. Weng, L.Y. Li, The Coupling Coordination Degree and Spatial Correlation Analysis on Integrational Development of Tourism Industry and
Cultural Industry in China, J. Economic Geography. 01(2016)178-185.

[4] B. Zhou, M.Y. Zhang, L.S. Zhong, Assessment of coupling coordination degree of tourism economy and cultural industry in Inner Mongolia, J. Journal of Arid Land Resources and Environment. 04(2019)203-208.

[5] Z.B. Liao, Quantitative Judgement and Classification System for Coordinated Development of Environment and Economy - A Case Study of the City Group in the Pearl River Delta, J. Tropical Geography.02(1999)171-177. 